\title{
Marx jornalista: a empiria a serviço da crítica da economia política*
}

\author{
Journalist Marx: empirical elements at the service of critique of political economy
}

\author{
Adriano Lopes Almeida Teixeira (1) \\ (1) Universidade Federal do Espírito Santo
}

\begin{abstract}
This article seeks to highlight the importance of the journalistic activities developed by Marx between the years 1848 and 1857 for the process of elaborating his critique of political economy. Without abandoning his theoretical work, the journalism and his involvement with the apprehension of the practical aspects of social reality made possible to Marx the refinement of two essential aspects for the elaboration of his critique: the form and content of the categories of political economy. Therefore, in addition to theoretical developments of that period contained both in London Notebooks, as in epistolary Marx-Engels, the empirical elements appear as a fundamental moment in Marx's theoretical-methodological trajectory, which would culminate in the elaboration of the Grundrisse in the years 1857-1858.
\end{abstract}

\section{Keywords}

journalism, empirical elements, critique of political economy, dialectical method.

JEL Codes B14, B41, B51.

\section{Resumo}

Este artigo busca evidenciar a importância das atividades jornalísticas desenvolvidas por Marx entre os anos de 1848 e 1857 para o processo de elaboração de sua crítica da economia política. Sem abandonar seus trabalhos teóricos, o jornalismo e seu envolvimento com a apreensão dos aspectos práticos da realidade social possibilitaram a Marx o refinamento de dois aspectos essenciais para a elaboração de sua crítica: a forma e o conteúdo das categorias da economia política. Por isso, para além dos desenvolvimentos teóricos daquele periodo contidos tanto nos Cadernos de Londres, quanto no epistolário Marx-Engels, a empiria aparece como momento fundamental da trajetória teórico-metodológica de Marx, que culminaria na elaboração dos Grundrisse nos anos de 1857-1858.

\section{Palavras-chave}

jornalismo, empiria, crítica da economia política, método dialético.

Códigos JEL B14,B41,B51.

* Este artigo é uma versão modificada de um dos capítulos da tese de doutorado do autor, A genealogia da mais-valia: filosofia, economia e crítica da economia política (2014). 


\section{Introdução}

De forma não intencional, jornalismo e teoria se imbricaram na trajetória intelectual de Marx, num processo de retroalimentação constante, interrompido em alguns momentos pelas vicissitudes de uma vida constantemente atribulada por questões financeiras, familiares e políticas. Se é bastante conhecida a proposição de que não se pode fatiar Marx, e que seu pensamento só pode ser relativamente compreendido por uma perspectiva totalizante que englobe filosofia, economia e prática política, suas atividades jornalísticas foram uma espécie de amálgama desses três elementos.

Como bem destaca Heinrich (2018, p. 32) em recente biografia de Marx,

As ideias cientificas desenvolvidas influenciavam as atividades jornalísticas e políticas; por outro lado, essas atividades muitas vezes exigiam uma interrupção dos trabalhos cientificos, levantando novos temas e problemáticas, levando à formação de novos conceitos e, assim, influenciando a própria pesquisa científica.

Com efeito, era no calor de suas atividades profissionais como jornalista que Marx reunia elementos para seu processo de elaboração teórica ao mesmo tempo que buscava incendiar o cenário político com artigos que denunciavam a opressão sofrida pela classe trabalhadora e divulgavam a iminência da revolução.

As atividades jornalísticas de Marx começam no ano de 1842 na Gazeta Renana. Não tendo conseguido ocupar uma cátedra na Universidade de Berlim, restou-lhe buscar o jornalismo como meio de sobrevivência. Para autores como Krätke (2008a, p. 162), aquele ano representou o início de uma longa relação com a economia política.

O presente artigo vai se concentrar nas atividades jornalísticas desempenhadas por ele a partir de 1848, ano da eclosão de diversas revoluções pela Europa. Foi somente a partir de A miséria da filosofia, de 1847, que Marx esboça uma crítica esteada não somente no seu amplo conhecimento filosófico e jurídico, mas também na teoria econômica legada pelos economistas clássicos, objeto de estudo intensivo desde sua chegada a Paris, em 1844.

Esse procedimento não significa concordar com uma suposta cisão entre o Marx jovem e o maduro. Apenas se reconhece que, entre 1842 e 1847, a vida profissional de Marx foi entrecortada por diversos reveses no campo político, que o impediram de atuar de forma contínua pelos jornais por onde passou, o que somente iria acontecer a partir de sua chegada a Londres, no final de 1849. 
O ano de 1848 é, pois, emblemático na configuração do Marx jornalista. Ano de publicação de $O$ Manifesto Comunista, ele - que já tinha feito seu ajuste de contas com a filosofia alemã através de obras escritas sozinho e com Engels, ajuste consumado em $A$ ideologia alemã - reconhecia que, embora tivesse acumulado um estoque de conhecimento suficiente para confrontar Proudhon na Miséria da filosofia, seu conhecimento teórico em economia precisaria sofrer considerável evolução. Por isso, o Marx que chega ao final da década de 1840 é o Marx que reconhecia tanto a derrota temporária do projeto político quanto a necessidade de dedicar mais tempo ao estudo da economia, o que significaria, na mesma medida, se abastecer de maior conteúdo empírico.

No seu embate com Proudhon, em 1847, Marx, já conhecedor da filosofia hegeliana, critica o uso inadequado que o autor de A filosofia da miséria faz de Hegel. Embora esse autor tenha recebido os estilhaços dos ataques proferidos por Marx e Engels à filosofia especulativa em obras como $A$ sagrada família e $A$ ideologia alemã, não parece que Marx tenha em algum momento pretendido uma ruptura completa com Hegel. A dialética legada por Hegel, transformada e aportada no projeto de compreensão de uma sociedade reconhecidamente mistificada, necessitava que suas estruturas essenciais estivessem em relação direta com as condições concretas da realidade. Por isso, o jornalismo iria se apresentar como atividade capaz de arramar as pontas que estavam soltas no seu projeto, fato que alcançaria plenitude no período londrino.

A partir de 1949, já em Londres, Marx entra em ritmo alucinante de trabalho para garantir o próprio sustento material. Sem abandonar totalmente os estudos teóricos, dedica-se a intensas pesquisas de cunho empírico para os artigos jornalísticos que tinha que produzir. Essa etapa da vida de Marx é o momento em que ele amplia seus conhecimentos de economia visando à realização da crítica da economia política. Se, em Miséria da filosofia, de 1847, ele deu um passo à frente na análise teórica da totalidade da reprodução capitalista, tratava-se agora, em meio às atividades de apropriação da realidade concreta, de preparar as condições para a realização da crítica.

A importância, portanto, do período entre 1848 e 1857 para o enriquecimento teórico do projeto marxiano contrasta com certo descaso da tradição marxista com os trabalhos jornalísticos de Marx. Pino (2013, p. 22) lembra que a indiferença quanto à importância do jornalismo para os objetivos teóricos de Marx é decorrente da primazia concedida pela tradição 
marxista ao Marx filósofo e ao Marx economista. Este artigo, ao contrário, busca situar o jornalismo de Marx como etapa fundamental de constituição dos elementos teóricos e metodológicos da crítica da economia política.

A forma como o presente artigo foi dividido reflete a dificuldade de separar o jornalista do filósofo, do ativista político ou do economista, pois, como já mencionado, eles se interseccionam. Na próxima seção, abordaremos a trajetória de Marx desde a fundação da Nova Gazeta Renana em Colônia, em 1848, até o ano de 1851, quando, já em Londres, recebe convite de Charles Dana, editor do jornal norte-americano New York Tribune para ser correspondente na Europa e escrever uma série de artigos sobre os eventos políticos ocorridos na Alemanha. Na seção seguinte, a terceira, o foco estará sobre o conjunto das atividades desempenhadas por Marx desde o convite de Charles Dana até a elaboração dos Grundrisse. Por fim, na última seção buscaremos evidenciar a relação umbilical entre atividades jornalísticas e elaboração teórica na evolução do pensamento de Marx durante aquele período, com foco nos Cadernos de Londres, escritos entre 1850 e 1853, e no epistolário Marx-Engels, seguindo-se, então, brevíssimas considerações finais.

\section{Marx (1848/1851): da Nova Gazeta Renana ao New York Tribune}

A rigor, não há razões para contestar o depoimento dado por Marx quanto a ter interrompido seus estudos formais de economia durante os anos de 1848 e 1849. Ele, até então, tinha se debruçado no estudo dos teóricos mais proeminentes no campo do socialismo e da economia política, através de análise cuidadosa, quase sempre parágrafo a parágrafo, de suas principais obras. De fato, essa prática é interrompida com a ida de Marx em 1848 para Colônia, onde, no calor da revolução que inflamava os alemães, ele se dedicaria à publicação diária de um jornal, a Nova Gazeta Renana (NGR), que em algumas edições era acompanhado por volumosos suplementos, demandando quase o seu tempo total disponível. Sobre a importância desse jornal na trajetória intelectual de Marx, Claudín (1985, p. 93) diz que:

Na NGR [Nova Gazeta Renana] podemos seguir o passo a passo como interpretam Marx e Engels o processo revolucionário, suas opções táticas e estratégicas e suas primeiras generalizações teóricas da prática que estão vivendo; vemos nascer muitas das reflexões e teses que encontraram logo expressão mais 
desenvolvida - ou seriam retificadas - nos textos clássicos sobre a revolução de 48: Revolução e Contrarrevolução na Alemanha, A luta de classes na França, O 18 Brumário de Luís Bonaparte.

Nesse período, Marx teve que dividir o seu tempo com questões paralelas a sua atividade principal, como os processos judiciais e a militância política. Se, por um lado, Marx na Nova Gazeta Renana se afastava dos tradicionais compêndios de economia política, por outro, adquiria paulatinamente a capacidade de estar em fina sintonia com a ordem do dia. Tornava-se um exímio analista de conjunturas.

Sua ida para a Alemanha significou um afastamento das atividades políticas que desempenhava no Comitê Central em Bruxelas, mas também uma aproximação dos fatos políticos que norteavam a causa proletária na Alemanha. Percebe-se, assim, que o perfil de sua atuação, bem como o perfil do órgão que comandava, compelia Marx a se calçar de ampla base empírica. Afastava-se dos estudos da economia política, mas não da análise dos fatos econômicos do dia a dia, uma prática que atenderia aos seus propósitos de dar à economia política uma base científica, que significava a recusa às leis abstratas como ponto de partida.

É essa nova configuração das suas investigações que permite relativizar a afirmação de Marx sobre a interrupção dos seus estudos econômicos no período da Nova Gazeta Renana. Como alerta Chasin (1993, p. 33), "cabe atentar bem para o significado intrínseco da afirmação, pois, não se há de supor, evidentemente, que Marx interromperia seus estudos econômicos por tão largo período em troca de alguma bagatela".

Os olhos de Marx permaneciam, pois, atentos aos fatos econômicos da época, como mostram alguns dos seus textos publicados naquele jornal. Os artigos citados a seguir são apenas alguns, entre outros, que abordam a temática econômica e que são elencados prioritariamente, e em ordem cronológica, devido à ênfase própria dos seus títulos: "O projeto de lei sobre o empréstimo compulsório e sua exposição de motivos" (Marx, 2010, p. 167-170), de 26 de julho de 1848, artigo no qual, de forma sucinta, Marx menciona categorias como circulação, dinheiro, capital e juros; "A Gazeta de Colônia sobre o empréstimo compulsório" (Marx, 2010, p. 191-192), de 04 de agosto de 1848, que contém elementos sobre a questão fiscal da Prússia; "O discurso de Proudhon contra Thiers" (Marx, 2010, p. 195-198), de 05 de agosto de 1848, em que Marx critica a ideia de criar um Banco Nacional com consequente redução dos juros a zero; "A Bélgica, 'Estado-Modelo'" (Marx, 2010, p. 199-202), de 07 de agosto de 1848, com o uso 
de dados demográficos, comércio exterior, produção da indústria nacional etc.; "O orçamento dos Estados Unidos e o germano-cristão" (Marx, 2010, p. 373-376), de 07 de janeiro de 1849; "A situação financeira prussiana sob Bodelschwingh e consortes" (Marx, 2010, p. 440-449), de 17 de fevereiro de 1849; "Outra contribuição sobre a administração financeira velho-prussiana" (Marx, 2010, p. 454-456), de 23 de fevereiro de 1849; "A situação do comércio" (Marx, 2010, p. 484-488), de 07 de março de 1849 e "Os bilhões" (Marx, 2010, p. 513-517), de 16 de março de 1849, com elementos da política monetária do Governo Provisório na França. No dia 05 de abril de 1849, Marx publica o primeiro editorial, de um total de cinco, do que ficou conhecido como Trabalho Assalariado e Capital.

Engels menciona os textos da Nova Gazeta Renana como um dos momentos, além de O Manifesto Comunista, em que Marx consegue, com sucesso, aplicar a concepção materialista da história "para explicar acontecimentos políticos contemporâneos. (...) Tratava-se, pois, de reduzir, seguindo a concepção do autor, os acontecimentos políticos a efeitos de causas que, em última instância, eram econômicas" (Engels, 1953, p. 93).

$\mathrm{Na}$ década seguinte, e sobretudo até a publicação de $O$ Capital, a feição empírica dos trabalhos de Marx permanece. Em Londres, a partir de 1850, volta aos estudos de economia política, em alguns momentos de forma simultânea às atividades jornalísticas, buscando construir uma teoria do valor própria, num movimento que não poderia prescindir dos dados econômicos e estatísticos constantes das mais diversas fontes, como jornais, relatórios de agências oficiais, cadernos dos inspetores de fábrica, os Blue Books (cadernos azuis, publicados pelo Parlamento Britânico com informações sobre a história econômica e diplomática do país) etc.

O objeto de estudo de Marx, a sociedade burguesa, não poderia ser compreendido sem o apelo ao empírico. De certa forma, o que aqui é apresentado como resultado do entendimento de Marx de que o método correto exigia submeter as categorias da economia política à sua concepção materialista da história - o que requeria pesquisas mais profundas sobre elementos da vida material que até já tinham sido tratados pelos clássicos - tem também o seu lado fortuito, pois Marx foi obrigado a se apegar ao jornalismo como única fonte de sobrevivência. Se a adoção da carreira jornalística esteve longe de ser uma escolha planejada e espontânea, não se diga o mesmo da forma como essa contingência foi direcionada para seus propósitos de construir uma crítica da economia política. É razoável 
entender que a publicação dos textos, especialmente na Nova Gazeta Renana, se tinha objetivos políticos, tinha também certa funcionalidade teórica, muitas vezes com a proeminência desta última sobre aqueles, como se pode extrair da queixa ${ }^{1}$ de Engels, testemunhada por $\operatorname{Born}^{2}$ (1981, p. 16) ao visitar Marx como editor do referido jornal em janeiro de 1849:

\begin{abstract}
"Ele não é e nunca será um jornalista", dizia ele. "Passa o dia inteiro estudando minuciosamente um artigo de fundo que outra pessoa levaria umas duas horas para fazer, como se ele concernisse ao manejo de um problema filosófico profundo. Altera e aprimora, e depois modifica as alterações, e, graças a seu rigor incansável, nunca consegue terminar na hora certa."
\end{abstract}

Marx chega a Londres no final de agosto de 1849 decidido a dar prosseguimento às suas atividades políticas e teóricas. Envolve-se com atividades de apoio a refugiados políticos alemães, com a reorganização da Liga Comunista e com a criação de um jornal alemão, de publicação mensal, cujo objetivo mais uma vez, além do próprio nome escolhido, demonstra o processo de retroalimentação entre aquelas duas atividades: "investigar de modo detalhado e científico as relações econômicas que constituem a base de todo o movimento político." (Claudín, 1985, p. 228). Assim como o seu jornal da Renânia, o nome escolhido foi Neue Rheinische Zeitung (Nova Gazeta Renana), distinguindo-se apenas quanto ao acréscimo do termo Politisch-ökonomische Revue (Revista Econômico-Política). Segundo Engels, Marx tinha acompanhado os principais acontecimentos dos anos 1848-1849 de tal forma, que estava apto a escrever sobre a situação econômica e política das principais nações europeias, sem as perturbações que a proximidade dos eventos pode causar a um analista que tenha participado dos fatos ocorridos (Engels, 1953, p. 94).

De fato, política e economia se imbricam nos três únicos números do jornal, publicados em forma de revista. Os temas versam sobre conjuntura econômica e política internacional tanto no primeiro número (janeiro-

1 Queixa semelhante fora feita anos antes por Arnold Ruge (1981, p. 8), que, com Marx, fundou no ano de 1844, em Paris, os Anais Franco-Alemães: "Ele tem uma personalidade peculiar - perfeito como erudito e escritor, mas um completo desastre como jornalista. Lê muito; trabalha com uma intensidade incomum e tem um talento crítico que de vez em quando degenera numa dialética temerária. Mas não termina nada, interrompe tudo e volta a mergulhar num oceano de livros. (...) É irritadiço e exaltado, particularmente quando trabalha até adoecer e não vai para a cama por três, até quatro noites seguidas."

2 Stephan Born foi um tipógrafo e revolucionário alemão, membro da Liga Comunista, com participação ativa na revolução de 1848. A citação faz parte de suas memórias, publicadas em 1898, disponíveis em <https://www.gutenberg.org/files/55895/55895-h/55895-h.htm>, p. 196, acesso em 14/08/2018. 
-fevereiro de 1850) quanto nos dois outros (março-abril e maio-outubro de 1850). Este último número antes da falência do jornal foi precedido por um aprofundamento da análise econômica por parte de Marx, que chega à conclusão de que "a crise comercial contribuiu infinitamente mais para as revoluções de 1848 do que a revolução para a crise comercial" (Musto, 2011, p. 42). Essa constatação recrudesce a visão que Marx já defendia desde a década anterior, especialmente na Nova Gazeta Renana, de recusar o método pelo qual a revolução seria fruto de algum plano habilmente preparado, o que gerava forte oposição de quadros políticos aliados. ${ }^{3}$

Antes de entrar em completo isolamento político, "uma grande quantidade de artigos econômicos nas Notes to the People e no People's Paper foram escritos com a colaboração direta de Marx" (Krätke, 2008a, p. 163). Com o isolamento imposto pelas circunstâncias, Marx permanece em Londres, enquanto Engels abandona o jornalismo e volta para Manchester, onde se empregaria na empresa têxtil de seu pai, a Ermen \& Engels. Por alguns meses, Marx ministra cursos de economia para os amigos em sua própria casa, o que o mantém em contato com a teoria, conforme depoimento de Wilhelm Liebknecht, amigo e discípulo de Marx, prestado em 1896 (Enzensberger, 2009, p. 130-131).

\section{Marx (1851/1857): o nascedouro dos Grundrisse}

Com efeito, a resistência de Marx em participar dos projetos de preparação para a revolução guardava relação com a sua convicção de que era necessário antes compreender cientificamente a natureza e a estrutura de funcionamento da sociedade capitalista. A dissolução da Liga Comunista acontece em 17 de dezembro de 1852, mas, desde 1851, o afastamento das atividades políticas dá a Marx a oportunidade de se voltar para os estudos de economia política. Ele não seria membro de nenhum partido político pelos dez anos seguintes.

3 O Comitê Central da Liga dos Comunistas de Londres envia uma carta à Direção Geral, em princípios de 1851, contendo ataques a Marx e Engels e explicando os motivos da divergência: "(...) A única diferença entre eles e nós com referência aos princípios - quando ainda trabalhávamos juntos - era que esses homens afirmavam a necessidade de prosseguir por pelo menos durante 50 anos mais em oposição, isto é: de atuar de forma meramente crítica, enquanto nós afirmávamos que com uma adequada organização de nosso partido seríamos capazes de impor já na próxima revolução as medidas tendentes à instauração da sociedade proletária" (Enzensberger, 2009, p. 163-164). 
Esses acontecimentos impactariam positivamente o ritmo dos estudos de Marx que, em busca de respostas, empreende uma acelerada troca de cartas com Engels sobre temas da economia política. O ritmo na troca de cartas entre os dois seria tão intenso que às vezes uma carta era enviada antes que chegasse a resposta referente à carta anterior. Por isso, nos intervalos entre as "cartas teóricas", ${ }^{4}$ Marx e Engels se correspondiam sobre os mais variados assuntos. Sem saber ainda que voltaria a se ocupar com tarefas jornalísticas, Marx escreve a Engels em 11 de fevereiro de 1851: "Eu gosto muito do isolamento do público no qual nos encontramos. Tem a ver com nossa atitude e nossos princípios" (Marx; Engels, 1982, p. 286). Em janeiro de 1851, Wilhelm Pieper, um jovem filólogo alemão que foi secretário de Marx, escreve a Engels, dizendo: "Marx tem estado muito isolado. Seus únicos amigos são John Stuart Mill e Lloyd. Quando alguém chega em sua casa, em lugar de cumprimentos é saudado com categorias econômicas" (Enzensberger, 2009, p. 168).

Engels passaria aproximadamente os próximos 20 anos em Manchester, naquilo que ele considerou seu próprio exílio pessoal. O epistolário MarxEngels, tema que será retomado mais adiante, torna-se, desde então, um repositório valioso do desenvolvimento teórico conjunto desses dois autores. Eles, que escreveram diversas obras juntos, tinham nas cartas a única possibilidade de interação. Em 07 de janeiro de 1851, Marx escreve: "Te escrevo somente para submeter a seu exame uma pequena questão teórica de natureza político-econômica. Comecemos desde o princípio: sabes que, segundo a teoria de Ricardo, a renda não é mais do que a diferença entre custo de produção e o preço do produto agrícola (...)" (Marx; Engels, 1982, p. 258). Engels responde somente em 29 de janeiro de 1851. Em 03 de fevereiro, Marx escreve longa carta a Engels, com grande quantidade de dados referentes à circulação monetária na Inglaterra. Engels envia seu parecer a Marx em 25 de fevereiro de 1851. Em 02 de abril, Marx informa a Engels que teve que interromper seus estudos devido aos problemas financeiros e de saúde de Jenny, sua esposa, mas que, dado o estado adiantado de suas pesquisas sobre economia, em cinco semanas concluiria a sua Economia Politica e se dedicaria a outro campo de aprendizagem no Museu Britânico (Marx; Engels, 1982, p. 325).

Em agosto de 1851, Marx recebe convite de Charles Dana, editor do jornal norte-americano New York Tribune, para ser correspondente na Eu4 As cartas aqui recuperadas são as que fornecem pistas do desenvolvimento teórico de Marx. Por isso denominá-las "cartas teóricas". 
ropa e escrever uma série de artigos sobre os eventos políticos ocorridos na Alemanha. Esses artigos seriam escritos por Engels, a pedido de Marx, que ainda não dominava o idioma inglês. Além dessa dificuldade, que seria logo superada, Marx não queria parar seus estudos de economia política. Em carta de 14 de agosto de 1851, escreve a Engels: "Tens que me ajudar, agora que estou ocupadíssimo com a economia política" (Marx; Engels, 1982, p. 425). Durante 11 anos, de agosto de 1851 e fevereiro de 1862, Marx, com a participação de Engels, enviou artigos semanais para aquele jornal, que era publicado em três versões diferentes: o New York Daily Tribune, o New York Semi-Weekly Tribune e o New York Weekly Tribune. Segundo Musto (2011, p. 47), "o primeiro publicou 487 artigos, dos quais mais da metade reapareceram no New York Semi-Weekly Tribune e mais de um quarto no New York Weekly Tribune", além dos que foram recusados por Charles Dana. Daquele total, 350 foram de autoria de Marx, 125 de Engels (dos quais a maioria foi sobre assuntos militares) e 12 escritos em conjunto (McLellan, 1990, p. 307).

Aproximadamente um terço dos artigos de Marx destinava-se à análise de assuntos financeiros e econômicos da atualidade, principalmente da Grã-Bretanha, mas também de outros países e da economia mundial como um todo (Krätke, 2008a, p. 163). Nesses artigos, Marx se expressa de maneira aprofundada sobre temas que reaparecem em $O$ capital sem o mesmo nível de profundidade, como o mercado monetário e a legislação bancária, com exceção dos temas relacionados à legislação fabril, expostos detalhadamente por Marx naquela obra (Krätke, 2007, p. 129). Certamente, este é mais um exemplo de como a exposição dos resultados da pesquisa, em Marx, situa-se de forma aparentemente desvinculada da investigação, pois, em $O$ capital, as digressões mais específicas sobre jornada de trabalho e legislação fabril aparecem a partir do capítulo oito, enquanto a exposição da mais-valia acontece no capítulo quatro. $O$ vínculo entre investigação e exposição subsequente fica claro quando se nota, por exemplo, que, para a elaboração posterior da categoria mais-valia relativa, a complexa questão da relação entre produtividade e intensidade do trabalho teve que ser analisada cuidadosamente por Marx, "que argumenta estritamente em termos da teoria do valor: o que os proprietários da fábrica perdiam pela limitação legal da jornada de trabalho, em tempo de trabalho absoluto, recuperavam através da intensificação do tempo de trabalho" (Krätke, 2007, p. 131). 
Krätke menciona, ainda, a seção quinta do livro III de $O$ capital como consistindo, em grande parte, de matérias daquele período. Ademais, temas como

(...) crises, mercado mundial, estruturas internacionais do comércio, por meio das quais umas nações exploram outras, colônias, colonialismo e sua importância para o desenvolvimento do capitalismo, e diferentes formas de finanças públicas e economia pública - somente foram tratadas por Marx em seus artigos de jornal. Algumas das mais sofisticadas reflexões sobre o estado moderno, seu desenvolvimento histórico dentro do contexto do sistema europeu de estados nacionais, e o desenvolvimento das principais formas da política nas sociedades burguesas modernas são somente encontradas numa série de artigos escritos por Marx em diversas ocasiões (Krättee, 2008a, p. 163-164).

É necessário compreender a teoria de Marx como resultado de experimentos, tentativas, correções, descobertas, recuos e avanços dentro de um processo que significava acompanhar um objeto histórico no seu próprio ritmo. Obviamente, Marx não sabia de antemão algo que ele ainda teria que descobrir. A evolução dos seus conhecimentos empíricos e do seu instrumental metodológico precisava ser acompanhada em igual medida pela evolução dos seus conhecimentos teóricos, no mesmo sentido em que ontologia e epistemologia caminham juntas. A premência da busca pelo sustento, aliada a outros projetos que surgiam nesse meio tempo, adiava o esperado livro sobre economia. De certa maneira pode-se dizer que nem os trabalhos jornalísticos interromperam os estudos de economia, nem estes interromperam aqueles. Marx era "o jornalista e economista crítico, consciente de viver um período turbulento do capitalismo, e que comparou a rápida expansão do mercado global durante a década 1849-1858 aos mais brilhantes períodos do século XVI" (Krätke, 2007, p. 134-135).

De fato, a consolidação do modo de produção capitalista é apreendida por Marx. A realidade era analisada por ele nos marcos de sua concepção materialista da história, num momento em que se generalizavam tanto as forças produtivas especificamente capitalistas quanto as relações sociais capitalistas de produção. No prefácio de Contribuição à crítica da economia política, de 1859, menciona "o novo estágio de desenvolvimento em que esta [a sociedade burguesa] parecia entrar com a descoberta do ouro na Califórnia e Austrália" (Marx, 1986, p. 27) como fator que o levou a recomeçar os estudos. Krätke (2007, p. 135) acrescenta outras circunstâncias históricas, como a revogação da lei de cereais, a enorme onda de imigração europeia etc.

Os trabalhos jornalísticos de Marx perduram até 1862, intercalado por diversos momentos em que a prioridade se volta para os estudos teóricos 
e até políticos. O 18 Brumário de Luís Bonaparte, considerada por muitos como sua obra histórica mais profunda, foi escrito entre dezembro de 1851 e março de 1852, para uma revista mensal norte-americana, a Die Revolution. Nessa obra, Marx analisa os efeitos do golpe de 02 de dezembro de 1851 no contexto do conflito de classes existente na França. Ainda no mês de dezembro, escreve Revelações sobre o processo de comunistas de Colônia, e, entre maio e junho de 1852, escreve Os grandes homens do exílio, em que analisa os problemas internos entre os exilados no interior da Liga Comunista.

Se, entre 1850 e 1853, Marx esteve ocupado com os Cadernos de Londres, seus estudos teóricos seriam retomados em algum momento entre o fim de 1854 e o início de 1855 (Musto, 2011, p. 54). Simultaneamente a essas iniciativas, continuava produzindo artigos jornalísticos, embora suas publicações no New York Tribune decrescessem. Em 1853, 80 artigos de Marx foram impressos naquele jornal. Em 1854 o número se repete, mas, no ano seguinte, cai para 40, e, em 1856, para 24 (Mcllelan, 1990, p. 306).

Os artigos de Marx produzidos em 1856 focavam principalmente as crises monetárias na Europa (Krätke, 2008a, p. 163), tendo escrito, em junho de 1856, três artigos sobre o Crédit Mobilier (Marx; Engels, 1986, p. 8-24), banco francês fundado pelos irmãos Péreire, principal instrumento da política financeira de Napoleão III. Os irmãos Isaac e Jacob Émile Péreire criavam sociedades por ações, através das quais lançavam títulos de curto prazo na Bolsa e captavam recursos de pequenos investidores para o banco. Marx o considerou "como um dos maiores fenômenos de nossa época".

Nos dois anos seguintes, Marx e Engels escreveriam 117 artigos, sendo 98 de autoria de Marx e 19 de Engels. Dividindo esses artigos em blocos temáticos, vê-se que as crises econômicas são o segundo tema mais abordado, com 17 artigos, logo atrás da Revolta dos Sipaios, com 19. Outros seis artigos tratam do sistema bancário europeu, 11 da situação política da Grã-Bretanha, e o restante sobre questões políticas, sociais e bélicas diversas (De Paula, 2011, p. 133-134). "Nestes artigos, Marx fazia uso frequente do material que estava coletando diligentemente para o seu 'livro sobre a crise'" (Krätke, 2008a, p. 165).

Em abril de 1857, Marx recebe outro convite de Charles Dana, desta vez para enviar artigos para o New American Cyclopaedia, em forma de verbetes que, em sua maioria, tratariam de temas biográficos e militares. Nesse 
período, a maior parte dos trabalhos fica por conta de Engels, para que Marx possa dedicar mais tempo a sua pesquisa. Um total de 67 artigos é publicado até o final de 1858, sendo 51 de autoria de Engels e 16 de Marx (Mcllelan, 1990, p. 307).

Com efeito, mais do que qualquer obrigação contratual, as crises econômicas foram o acicate que conduziu Marx a iniciar a elaboração dos Grundrisse..$^{5}$ A crise, que na visão dele finalmente chegaria, ou, conforme suas próprias palavras, o dilúvio, seria a conjuntura perfeita para a deflagração dos ideais revolucionários. Por isso, dizia ele a Engels, em carta de 08 de dezembro de 1857: "Eu trabalho como um louco, noites inteiras adentro, para organizar meus estudos econômicos, para por às claras pelo menos os elementos fundamentais antes do dilúvio" (Marx; Engels, 1983b, p. 217). Em outra carta a Engels, de 18 de dezembro, descreve mais uma vez o ritmo alucinante dos seus trabalhos: "Eu estou trabalhando muito, como regra até às 4 horas da manhã. Estou envolvido em uma, tarefa dupla: 1. Elaborar os contornos da economia política (...); 2. A atual crise (...)" (Marx; Engels, 1983b, p. 224). Por ocasião dessa carta, Marx realizava uma dupla empreitada, ilustrando mais uma vez a vinculação entre jornalismo e teoria: ao mesmo tempo que escrevia sua obra teórica, os Grundrisse, compilava os Cadernos da Crise (outubro de 1857 a fevereiro de 1858), que consistia de notas variadas extraídas de jornais sobre a evolução da crise, movimentação da bolsa de valores, falências, etc. (Musto, 2011, p. 58). Esse material totalizaria mais de quinhentas páginas impressas para publicação no volume IV/14 da MEGA2 (Krätke, 2008b, p. 175).

Sobre os efeitos que as intensas pesquisas desenvolvidas por Marx na fundamentação de seus artigos jornalísticos teve no seu desenvolvimento teórico, os seus depoimentos parecem ser contraditórios. Por um lado, diz, em carta ao amigo Cluss, de 15 de setembro de 1853: "A contínua porcaria jornalística me aborrece. Toma muito tempo, dispersa meus esforços e, na análise final, não é nada. Por mais independente que se queira ser, ainda se é dependente do jornal (...) Obras puramente científicas são algo completamente diferente" (Marx; Engels, 1983a, p. 367). Por outro, sugere uma relação positiva entre suas atividades no jornalismo e seus estudos de economia política, no prefácio de Contribuição à crítica da economia política, em 1859:

5 Como assinala Krätke (2008b, p. 169), "Sem a crise mundial de 1857-8, Marx provavelmente não teria escrito os Grundrisse". 
Minha colaboração, já de oito anos, com o primeiro jornal anglo-americano, o New-York Tribune, tem exigido uma extraordinária dispersão dos estudos, uma vez que apenas excepcionalmente me ocupo com o jornalismo dito. Contudo, artigos sobre fatos econômicos de destaque, ocorridos na Inglaterra e no continente, constituem parte tão significativa da minha contribuição que me vi obrigado a familiarizar-me com pormenores que ficam fora do ramo da ciência da Economia Política propriamente dita (Marx, 1986, 27).

Para Krätke (2007, p. 129), "como um pensador da economia política, Marx aprendeu com seu trabalho jornalístico mais do que ele estava disposto a admitir". Pino (2013, p. 20) é ainda mais enfático ao dizer que a lista de linhas temáticas trabalhadas por Marx, especialmente no New York Tribune "constitui, desde uma perspectiva teórica, um trabalho de investigação, análise de dados e teste dos conceitos crucial na sua formação, através do qual poderá estabelecer no ano de 1858 - na frenética escritura dos Grundrisse (1857-1858) - a noção vertebral de sua crítica à econômica política: o conceito de mais-valia".

A conexão quase instantânea que Marx possuía com os últimos acontecimentos the permitia diminuir o hiato entre a ocorrência do fato e a sua análise. Se ele não era essencialmente um jornalista, como disse Engels referindo-se ao ritmo da fabricação de suas matérias, é necessário reconhecer que ele também tinha adquirido hábitos próprios de um jornalista quanto aos meios usados para ter acesso às informações. Seus defeitos como jornalista eram a razão da alta qualidade dos seus artigos, valorizados nos Estados Unidos por conta da profundidade de suas análises. O uso de suas fontes, relacionamento pessoal e de todos os recursos disponíveis que viabilizasse o acesso a dados de variados tipos, desde relatórios a livros de tiragem limitada, era prática típica do jornalismo que desautoriza uma construção caricata de Marx como teórico de gabinete.

Ao mesmo tempo que se dedicava à análise da realidade capitalista concreta e à luta política, esta última como contraface do uso de sua pena, Marx se empenhava em continuar os seus estudos de economia política, abandonados desde sua ida para Colônia. O jornalismo, pois, não constituiu uma "pausa teórica", um intervalo na trajetória intelectual de Marx. Nas palavras de De Paula (2011, p. 133), não se deve falar 
ções do movimento geral do capital como "particularidade" e como "singularidade", isto é, pela explicitação de suas formas fenomênicas de existência.

Retome-se, mais uma vez, a discussão sobre o papel fundamental da empiria para o método dialético de Marx. Enquanto em Miséria da filosofia ele hostiliza o método das abstrações de Proudhon, em Introdução de 1857, longe do contexto que impulsionou aquela obra, as abstrações são apresentadas como instrumento analítico fundamental. Nesta, Marx discorre sobre as "abstrações razoáveis", ${ }^{6}$ necessárias no processo de elaboração teórica que, diferentemente dos clássicos, teria que incorporar no âmbito de uma totalidade orgânica tanto os aspectos gerais referentes a toda e qualquer sociedade quanto os aspectos específicos de uma determinada formação social. Ele, portanto, reconhece que há determinações comuns a todos os modos de produção e que elas precisam ser integradas nos diversos elementos do desenvolvimento histórico. Importa, pois, reconhecer também as especificidades de cada etapa histórica. Por isso, as determinações mais gerais, juntamente com as específicas de uma determinada época, se articulam dentro das abstrações gerais como totalidades orgânicas. Deve-se ressaltar que as categorias econômicas que vão se constituindo ao longo da análise não são resultado de uma construção idealizada; elas são a expressão de relações reais de produção. Nesse sentido, pode-se dizer que, especialmente quanto à especificidade de cada etapa histórica, o conhecimento fornecido pelos trabalhos jornalísticos seria fundamental para que Marx evidenciasse as determinações próprias e contraditórias do modo de produção capitalista.

De fato, a crítica da economia política seria o resultado da aplicação ${ }^{7}$ de seu método às categorias da economia política analisadas no âmbito de relações históricas determinadas, para a qual concorreu tanto seu intenso trabalho de prospecção de dados empíricos quanto o estudo de inumeráveis livros nos mais variados terrenos, como economia política, história, filosofia, ciências naturais, matemática e, de forma original, também a lite-

6 "A produção em geral é uma abstração, mas uma abstração razoável, na medida em que, efetivamente sublinhando e precisando os traços comuns, poupa-nos a repetição. Esse caráter geral, contudo, ou esse elemento comum, que se destaca através da comparação, é ele próprio um conjunto complexo, um conjunto de determinações diferentes e divergentes. Alguns desses elementos comuns pertencem a todas as épocas, outros apenas são comuns a poucas" (Marx, 1986, p. 4).

7 Por aplicação não se entenda tratar-se de um procedimento específico, executado externamente ao objeto. 
ratura, dado que Marx usa, a todo instante, citações de Shakespeare, Balzac, Cervantes, Goethe, e outros, para ilustrar seus argumentos teóricos.

Segundo Pino (2013, p. 22), "os artigos do New York Tribune ensinariam a Marx que as contradições geradas pelo capital eram definitivamente insolúveis". Os Grundrisse são tributários desse amplo conhecimento empírico. Com efeito, o caminho teórico em direção à essência da mais-valia, por exemplo, inicia-se depois da análise de suas formas de manifestação. Sem dúvida, Marx havia avançado bastante no conhecimento sobre o funcionamento concreto do capitalismo. Havia estudado questões complexas e avançadas, como as relações entre os mecanismos de circulação monetária e os momentos de crises econômicas e de prosperidade, mas não se sentia ainda capaz de desvendar por completo a natureza interna da sociedade burguesa.

Nos Grundrisse, Marx busca reunir tudo o que havia apreendido nos seus anos de estudo teórico e de pesquisas empíricas. As experimentações na forma dialética de apresentação dos conceitos da economia política têm a empiria como um recurso imprescindível. Se no caminho que vai do concreto ao abstrato, a realidade mesma é o ponto de partida da teoria científica, no caminho de volta, do abstrato ao concreto, embora lógico, encontra correspondência também no próprio processo real da história. Entretanto, é preciso diferenciá-los, pois a exposição, como momento que sucede a investigação, busca ordenar, fazer o encadeamento lógico dos fatos já pesquisados.

Embora o presente trabalho não tenha a pretensão de analisar a "operacionalização" do método de Marx, a maneira diferenciada como a empiria é absorvida na exposição, vale recuperar indicações feitas por Ilienkov (1978, p. 34) em obra clássica, ao apontar para uma distinção entre o método dialético de tratamento dos fatos/dados empíricos e o método de elevar-se do abstrato ao concreto, ${ }^{8}$ considerando apenas uma exceção:

A tarefa específica do teórico que parte de toda esta informação sobre a realidade não consiste, por assim dizer, em dar a esta expressão "abstrata" uma forma ainda mais abstrata. Ao contrário, começa sempre procedendo a uma análise crítica de abstrações do nivel empírico do conhecimento e as refaz para seguidamente avançar, criticando a estreiteza e o subjetivismo de tais abstrações e destruindo as ilusões que elas contêm desde o ponto de vista da realidade em seu conjunto

8 A perspectiva de Ilienkov é semelhante à de Vygodsky, descrita por Fineschi (2009, p. 58) da seguinte forma: "Temos, então: a) uma íntima ligação entre o modo de exposição e a elevação do abstrato ao concreto, b) uma íntima ligação entre o modo de pesquisa e a elevação do concreto para o abstrato, c) a separação, no espaço e no tempo - embora não absoluta - de exposição e pesquisa." 
concreto. Neste sentido (e somente neste sentido), o passo do estado empírico ao estado racional do conhecimento aparece também como um passo "do abstrato ao concreto".

Em suma, o tratamento dos dados empíricos que subsidiam a análise de Marx é, em si, um procedimento dialético. Como diz Ilienkov (1978, p. 34), "este procedimento de análise permanece o mesmo, isto é, dialético, tanto no tratamento preliminar dos dados, como no curso de sua elaboração definitiva, ainda que, naturalmente, vá se aperfeiçoando na medida em que avança em direção a $O$ capital".

A título de ilustração, a descoberta da mais-valia foi resultado desse método, pois Marx partiu da circulação, do mundo visível, para chegar à conclusão de que a geração de valor novo só poderia ser encontrada em outra esfera, a produção, uma descoberta que aparece inicialmente em Miséria da filosofia, mas que só se potencializa metodologicamente com os seus primeiros artigos jornalísticos da década de 1850. Ressalte-se, todavia, que, ao longo daqueles anos, a profundidade e o acurado espírito crítico dos seus textos jornalísticos eram reflexos do aprimoramento paralelo dos seus conhecimentos teóricos. Como projeto nunca abandonado, a crítica da economia política requeria, especialmente a partir de Miséria da filosofia, que Marx elaborasse uma teoria do valor própria. Por isso, o estudo dos economistas políticos, notadamente aquele que foi sua referência maior naquela obra, David Ricardo, era um exercício obrigatório desde sua chegada a Londres.

\section{Jornalismo e teoria: os Cadernos de Londres (1850- 1853) e o epistolário Marx-Engels}

O período de elaboração dos Cadernos de Londres é entrecortado por diversas outras atividades e acontecimentos de cunho político e pessoal. Marx volta-se para os estudos teóricos, em relação aos quais suas cartas refletem todo um conjunto de questões, dúvidas e descobertas que acompanhavam a própria evolução de suas pesquisas. Como já mencionado, o período de isolamento, entre os anos de 1850 e 1851, permitiu que Marx retornasse às suas pesquisas sobre economia política. Nesse período, há um incremento acentuado no número de cartas trocadas por Marx e Engels, que era solicitado continuamente por aquele para dar sua opinião sobre as diversas questões teóricas que estava analisando. A partir de 1853 a quantidade 
de correspondências entre Marx e Engels avoluma-se novamente. Assim, não tendo Marx publicado obras econômicas no período entre a Miséria da filosofia e os Grundrisse, sua evolução teórico-metodológica entre 1850 e 1856 encontra registros tanto em suas anotações nos Cadernos de Londres ${ }^{9}$ quanto nas diversas cartas escritas. De setembro de 1850 a fevereiro de 1862, os estudos teóricos serão feitos, em maior ou menor intensidade, simultaneamente às atividades jornalísticas.

Dessa forma, na esteira do reconhecimento da importância dos trabalhos jornalísticos de Marx para sua elaboração teórica, cabe recuperar algumas das suas aquisições teóricas dessa fase. Foi com o iminente fechamento da Nova Gazeta Renana - Revista Político-Econômica que Marx voltou a estudar economia política. $O$ último número da revista foi publicado em novembro, já sob a nuvem negra da falência. Antes disso, em setembro de 1850, Marx dá início aos seus estudos teóricos, aproveitando-se do rico acervo do Museu Britânico. O jejum teórico de três anos é, pois, rompido com uma incessante pesquisa, os chamados Cadernos de Londres, compilados em 24 cadernos de notas durante os três anos seguintes, de setembro de 1850 a agosto de 1853. De acordo com a esquematização proposta por Musto (2011, p. 44-49), os Cadernos de Londres ${ }^{10}$ podem ser divididos em três grupos, conforme Tabela 1 , adiante.

O estudo sobre as crises econômicas feito nos primeiros cadernos, e que redundou no último número da Nova Gazeta Renana - Revista Político-Econômica, deu a Marx a percepção de que a revolução só aconteceria no ambiente de uma crise econômica. A análise das crises econômicas tornava-se, assim, objeto múltiplo do interesse de Marx, por constituir tema vital tanto para suas investigações teóricas quanto para suas atividades jornalísticas, e também para os projetos políticos posteriores.

Marx estuda incessantemente todos aqueles autores do primeiro grupo, que, excluído o Caderno VII, totalizam cerca de 600 páginas impressas da seção IV, volume V da MEGA2. Ainda não havia iniciado o Caderno VIII

9 Quanto aos Cadernos de Londres, há autores que mencionam sua publicação tardia na MEGA2 (1983-1991) como um dos fatores fundamentais que impossibilitou melhor compreensão do método de Marx (Fineschi, 2009, p. 58).

10 Obviamente, esta seção não pretende percorrer os Cadernos de Londres em todos os seus detalhes, mas apenas extrair alguns elementos essenciais da evolução intelectual de Marx. Por isso, além da esquematização e comentários de Musto (2011a), esta seção se vale da análise pormenorizada sobre esse tema feita por Leonardo de Deus (2010), e, em menor medida, do texto de Rubel (1974, p. 312-325). 
quando escreve a Engels, em carta de 02 de abril de 1851, informando o estado adiantado de suas pesquisas (Marx; Engels, 1982, p. 325).

Tabela 1 Cadernos de Londres (1850-1853)

\begin{tabular}{|c|c|c|c|}
\hline Grupo & Período & Cadernos & Principais temas e autores analisados \\
\hline $1^{0}$ & $\begin{array}{l}\text { Set./1850 - } \\
\text { mar./1851 }\end{array}$ & I-VII & $\begin{array}{l}\text { História e teorias das crises econômicas, dinheiro e crédito / } \\
\text { Thomas Tooke, James Taylor, Henry Thornton, Adam Smith, } \\
\text { David Ricardo }\end{array}$ \\
\hline \multirow{7}{*}{$2^{\circ}$} & \multirow{7}{*}{$\begin{array}{l}\text { Abr./1851 - } \\
\text { nov./1851 }\end{array}$} & VIII & Salário, renda da terra / David Ricardo, James Steuart \\
\hline & & IX-X & $\begin{array}{l}\text { Obras críticas sobre Ricardo / John Tuckett, Thomas Hodgskin, } \\
\text { Thomas Chalmers, Richard Jones, Henri Carey }\end{array}$ \\
\hline & & $\mathrm{XI}$ & $\begin{array}{l}\text { Condição da classe trabalhadora - salários, padrões de vida dos } \\
\text { trabalhadores, greves, trabalho infantil / J. Fielden, P. Gaskell, } \\
\text { Thomas Hodgskin (1) }\end{array}$ \\
\hline & & XII-XIII & $\begin{array}{l}\text { Química agrária - renda da terra / Justus Liebig, James F. W. } \\
\text { Johnston }\end{array}$ \\
\hline & & XIV & $\begin{array}{l}\text { Debate sobre a teoria da população, modos pré-capitalistas de } \\
\text { produção, colonialismo / Thomas Malthus, Archibald Alison, } \\
\text { Adolphe D. de La Malle, William H. Prescott. }\end{array}$ \\
\hline & & $\mathrm{XV}$ & História da tecnologia / Johann Poppe, J. Gray \\
\hline & & $\mathrm{XVI}$ & Diversas questões de economia política / Bastiat, Proudhon (2) \\
\hline $3^{\circ}$ & $\begin{array}{l}\text { Abr./1852 - } \\
\text { ago./1853 }\end{array}$ & XVII-XXIV & $\begin{array}{l}\text { Controvérsias históricas sobre a Idade Média, história da litera- } \\
\text { tura, da cultura e dos costumes. }\end{array}$ \\
\hline
\end{tabular}

Fonte: Musto (2011).

(1) Rubel (1974, p. 315); (2) Rubel (1974, p. 318). Caderno escrito entre outubro e novembro de 1851.

Ricardo era o alvo principal de Marx, que reserva a ele os Cadernos IV, VII e VIII, considerados "a parte mais importante dos [Cadernos de Londres] devido aos inúmeros comentários e reflexões pessoais que as acompanham" (Musto, 2011, p. 44). ${ }^{11}$ Quando termina o Caderno VII, Marx escreve dois outros cadernos de notas, sob o título Ouro: o sistema monetário perfeito, considerada por Musto (2011, p. 45) como, possivelmente, a "primeira formulação autônoma de Marx sobre a teoria do dinheiro e da circulação".

Marx retorna a Ricardo no Caderno VIII. Sua investigação tinha avançado anteriormente pelas concepções ricardianas sobre a renda da terra, conforme carta enviada a Engels, em 07 de janeiro de 1851, que lhe responde 11 Parte dos extratos sobre Ricardo, constantes dos Cadernos IV e VIII, aparecem no $3^{\circ}$ volume da edição dos Grundrisse, publicada pela Siglo Veintiuno Editores (2006). 
em 29 de janeiro, em tom aprobatório, sugerindo que Marx se apressasse para publicar sua economia (Marx; Engels, 1982, p. 271). Na carta seguinte, de 03 de fevereiro de 1851, Marx pretende discutir com Engels a currencytheory, e escreve a ele resumindo conclusões que já apareciam no seu Caderno IV. Na referida carta, além de resumir parte do conteúdo do Caderno IV, fica explícito o recurso aos dados empíricos:

Tooke faz a mesma afirmação; mas não encontrei nenhuma prova em sua história dos preços para 1843-1847. Note a importância do assunto. Em primeiro lugar, toda a teoria da circulação se encontra comprometida em sua própria base. Em segundo lugar, fica demonstrado como o desenvolvimento das crises, em que pese o sistema de crédito ser uma de suas condições, não tem relação com a currency, e que as insensatas regulamentações estatais podem ainda mais agravar (como em 1847) a crise. (Marx; Engels, 1982, p. 275).

A evolução nos conhecimentos de economia, notadamente quanto ao dinheiro, renda da terra, crédito, crises etc., não eram ainda suficientes para ensejar a construção de sua crítica. Com efeito, Marx não tinha ainda, nessa época, compreendido a dupla natureza da mercadoria e do trabalho, lacunas que obstaculizavam a progressão dos seus conhecimentos sobre os assuntos que já vinha estudando, ao mesmo tempo que o impulsionava a investigar mais.

No Caderno VIII, escrito entre abril e maio de 1851, Marx prossegue com a análise de Ricardo, que se estende, pelos Cadernos IX e X, escrito entre maio e julho de 1851, nas leituras que faz sobre os críticos daquele autor. O Caderno VIII se notabiliza, entre outros motivos, porque é nele que reaparece a intuição ${ }^{12}$ sobre a mais-valia, anteriormente esboçada em Trabalho assalariado e capital.

Tendo aceitado o convite para trabalhar como jornalista na New York Tribune, em agosto de 1851, Marx, paralelamente, continua suas pesquisas. Apesar de Engels ter insinuado, em carta de 29 de janeiro, que a "teoria da renda da terra" de Marx poderia até mesmo ser publicada (Marx; Engels, 1982 , p. 271), ele continuava a buscar no mundo real elementos para as soluções teóricas que ainda necessitava. Assim, entre setembro e novembro de 1851, escreve o Caderno XV, com temas sobre tecnologia, e o Caderno XVI, sobre temas diversos da economia política.

12 "Ele troca seu produto por outro cujo valor está determinado pelo tempo de trabalho nele empregado (...) $\bigcirc$ excedente não surge da troca, ainda que tão somente nela se realize. Surge de que deste produto que consome 20 dias de trabalho, o obreiro só obtém o produto de 10 etc., dias de trabalho. Na mesma medida em que cresce a força produtiva do trabalho, decresce o valor do salário" (Marx, 2006, p. 77). 
Apesar das múltiplas tarefas, já que, em março de 1852 - paralelamente à elaboração de $O 18$ Brumário - começa, de fato, a escrever para a New York Tribune (Krätke, 2007, p. 150), Marx inicia, em abril de 1852, o terceiro grupo de cadernos, que consubstanciam uma grande dispersão de temas (Musto, 2011, p. 49). Esses cadernos são finalizados em agosto de 1853, quando, então, Marx interrompe novamente seus estudos teóricos. No mês seguinte, escreve a Cluss, dizendo que tinha esperança de voltar a se isolar para trabalhar novamente na sua Economia (Marx; Engels, 1983a, p. 367). Isso acontece, como indica Musto (2011, p. 54), entre o fim de 1854 e o início de 1855, prosseguindo até meados desse ano. Com a nova interrupção de suas pesquisas ocorrida em meados de 1855, Marx só iria retornar aos estudos teóricos em junho de 1856, com os artigos para o The People's Paper sobre o Crédit Mobilier, em grande medida por causa de suas obrigações como jornalista.

A crise ainda não havia chegado e Marx intensifica seus estudos, que culminam com o início de elaboração dos Grundrisse, em agosto de 1857. A busca por dados empíricos e por todo tipo de informação útil para a construção da teoria se acelera. Como já mencionado, entre outubro de 1857 e fevereiro de 1858, Marx escreve os Cadernos da Crise. Também nesse período, as "cartas teóricas" entre Marx e Engels adquirem um perfil mais próximo de "cartas empíricas", pois, estando Engels mergulhado no dia a dia da indústria em Manchester, mantinha-se em condições de enviar a Marx dados sobre a crise, além de uma série de informações de caráter prático, relacionadas ao funcionamento das máquinas, ciclo de vida, disponibilidade de determinadas matérias-primas, situação de mercado de algumas indústrias, nível salarial etc.

Entre os dias 07 e 17 de dezembro de 1857, Engels escreve quatro cartas a Marx com as informações referidas. Em 29 de janeiro de 1858, Marx especifica ainda mais o pedido: "acabo de chegar a um determinado ponto, em meus trabalhos econômicos, sobre o qual desejo algumas explicações práticas, porque não tenho encontrado nada sobre isto nas obras teóricas" (Marx; Engels, 1983b, p. 256). Em outra carta, de 02 de março de 1858, Marx pede a Engels informações sobre o período médio de tempo para a renovação das máquinas (Marx; Engels, 1983b, p. 278). Engels responde com carta de 04 de março, que é seguida por outra de Marx, de 05 de março, agradecendo as respostas e enviando outras perguntas (Marx; Engels, 1983b, p. 279-284). 
Categorias econômicas como capital variável, capital constante, composição orgânica, força de trabalho, e sobretudo a mais-valia, são apreendidas por Marx não como construções arbitrárias de um pesquisador, mas como traços constitutivos do objeto analisado. A descoberta dessas categorias nos Grundrisse seria legatária tanto da trajetória teórica iniciada com a Crítica de 43 quanto das vicissitudes do laboratório da vida real na Londres dos anos 1850.

\section{Considerações finais}

Em certo sentido, é possível dizer que os Grundrisse representaram um recomeço para Marx, o que explica o fato de muitos analistas não levarem em conta os primeiros anos da década de 1850, ou simplesmente os caracterizarem como meros "antecedentes dos Grundrisse", dando, assim, um salto de Miséria da filosofia para os Grundrisse. Esta obra aparece, então, em algumas análises, como um momento mágico de Marx, quando toda a sua inspiração teórica floresce, em questão de meses, e se consubstancia numa obra magistral. Esquece-se, como já apontado na seção anterior, que os anos desde 1848 foram, de fato, o nascedouro dos Grundrisse, uma espécie de período de gestação da obra, filho temporão, que só veio à luz sob intensas dores de parto. Diga-se que, se os Grundrisse são um ponto de partida da crítica, são também um ponto de chegada de um longo período de investigação, o que invoca uma reconfiguração no peso dos anos de intermitentes estudos teóricos entre 1850 e 1856 para a compreensão do pensamento de Marx, pois realçam a mutualidade entre empiria e teoria na elaboração da crítica da economia política, um dos traços característicos do seu método dialético.

Os anos de Marx em Londres, especialmente os que antecederam os Grundrisse, precisam ser compreendidos como integrantes do itinerário teórico por ele percorrido desde a Crítica de 43 até a realização da crítica da economia política, consumada naquela obra. Naquela metrópole, lidou com imensa quantidade de informações relativas a aspectos práticos do funcionamento das máquinas, legislação fabril, tecnologia e diversos outros elementos que lhe seriam úteis na construção de categorias econômicas dentro dos Grundrisse. Por isso, a caracterização de Marx nessa época como, primordialmente, um economista crítico. Não era, a rigor, 
um economista, no sentido tradicional do termo. Sempre que entrava na seara dos economistas políticos, era para sair dela mais à frente, para exercitar a crítica, o método pelo qual aqueles conhecimentos eram analisados, incorporados ou descartados de forma parcial ou integral, e depois supra-assumidos.

Com efeito, Marx só se tornou Marx a partir do momento em que elaborou sua crítica da economia política, quando, enriquecido pelas determinações empíricas da sociedade capitalista, conseguiu, finalmente, submeter o objeto da economia política a uma operação específica, embora de cariz hegeliano. Mas isso não significa que tenha havido um Marx filósofo que depois se tornou um Marx economista. Como demonstrado, Marx nunca deixou de ser filósofo. A reconstrução de sua trajetória intelectual, notadamente a etapa referente ao laboratório londrino, permitiu apreender uma linha de continuidade, um fio condutor, que norteou os seus estudos desde A crítica de 43: a busca pela compreensão da forma de ser da sociedade burguesa. E a partir daí, o caminho que leva Marx de uma etapa exclusivamente filosófica à crítica da economia política é permeado de sinuosidades, capazes de confundir os observadores não dialéticos, levando-os a enxergar os períodos da evolução teórica de Marx como compartimentos estanques.

\section{Referências}

BORN, Stephan. Stephan Born. In: MCLELLAN, David (Org.). Karl Marx: Interviews and Recollections. Londres: Macmillan, 1981. p. 16.

CHASIN, José. Marx no tempo da Nova Gazeta Renana. Prefácio. In: MARX, Karl. A burguesia e a contra-revolução. 3. ed. São Paulo: Ensaio, 1993. p. 15-40.

CLAUDÍN, Fernando. Marx, Engels y la Revolución de 1848. 4. ed. Madri: Siglo XXI, 1985.

DE DEUS, Leonardo. Reconstrução categorial de O Capital à luz de seus esboços. A instauração da crítica da economia política (1857,1863). 259 f. Tese (Doutorado em Economia) - Faculdade de Ciências Econômicas, Cedeplar, Universidade Federal de Minas Gerais. Belo Horizonte, 2010.

DE PAULA, João. A. Marx 1857/1858: além dos Grundrisse. Revista da Sociedade Brasileira de Economia Politica. São Paulo, n. 30, p. 123-142, out. 2011.

ENGELS, Friedrich. Introdução. Lutas de classes na França de 1848 a 1850. In: MARX, Karl; Engels Friedrich. Obras escolhidas. São Paulo: Alfa-Ômega, 1953. v. 1. p. 93-198.

ENZENSBERGER, Hans. M. Conversaciones con Marx y Engels. Barcelona: Editorial Anagrama, 2009. 
FINESCHI, Roberto. Dialectic of the Commodity and Its Exposition: The German Debate in the 1970s - a Personal Survey. In: BELLOFIORE, R.; FINESCHI, R. Re-reading Marx: New Perspectives after the Critical Edition. Hampshire: Palgrave Macmillan, 2009. cap. 4, p. 50-70.

HEINRICH, Michael. Karl Marx e o nascimento da sociedade moderna. São Paulo: Boitempo, 2018. v. 1.

ILIENKOV, Evald V. Elevar-se de lo abstrato a lo concreto. In: DIAS, P. L. (Org.). El capital, teoria, estructura y método. México: Ediciones de Cultura Popular, 1978. V. 1. p. 27-83.

KRÄTKE, Michael. R. Journalisme et science. L'importance des travaux journalistiques de Marx pour la critique de l'économie politique. Actuel Marx, n. 42, p. 128-163, 2007.

KRÄTKE, Michael. R. The First World Economic Crisis: Marx as an Economic Journalist. In: MUSTO, Marcello. Karl Marx's Grundrisse: Foundations of the Critique of Political Economy 150 Years Later. New York: Routledge, 2008a. cap. 10. p. 162-168.

KRÄTKE, Michael. R. Marx's 'Books of CRISIS' of 1857-8. In: MUSTO, Marcello. Karl Marx's Grundrisse: Foundations of the Critique of Political Economy 150 Years Later. New York: Routledge, 2008b. cap. 10. p. 169-175.

MCLELLAN, David. Karl Marx. Vida e pensamento. Petrópolis: Vozes, 1990.

MARX, Karl. Para a crítica da economia política. Salário, preço e lucro. O rendimento e suas fontes. 2. ed. São Paulo: Abril Cultural, 1986.

MARX, Karl. Elementos Fundamentales para la crítica de la economía política (Grundrisse) 18571858. 13. ed. Madri: Siglo Veintiuno Editores, 2006.v. 3.

MARX, Karl. Nova Gazeta Renana. Tradução de Lívia Cotrim. São Paulo: Educ, 2010.

MARX, Karl; ENGELS, Friedrich. Collected Works. Moscou: Progress, 1982. v. 38.

MARX, Karl; ENGELS, Friedrich. Collected Works. Moscou: Progress, 1983a. v. 39.

MARX, Karl; ENGELS, Friedrich. Collected Works. Moscou: Progress, 1983b. v. 40.

MARX, Karl; ENGELS, Friedrich. Collected Works. Moscou: Progress, 1986. v. 15.

MUSTO, Marcello. A formação da crítica de Marx à economia política: dos estudos de 1843 aos Grundrisse. Revista Crítica Marxista. São Paulo, n. 33, p. 31-65, 2011.

PINO, Mario Espinosa. Introducción. In: MARX, Karl. Artículos periodísticos. Barcelona: Alba Clásica, 2013. p. 8-27.

RUBEL, Maximilien. Les cahiers d'études de Marx. In: RUBEL, Maximilien. Marx: critique du marxisme. Paris: Payot, 1974. p. 301-359.

RUGE, Arnold. Arnold Ruge. In: MCLELLAN, David (Org.). Karl Marx: Interviews and Recollections. Londres: Macmillan, 1981. p. 8-9.

\section{Sobre o autor}

Adriano Lopes Almeida Teixeira - adriano.teixeira@ufes.br

Universidade Federal do Espírito Santo, Vitória, Espírito Santo, Brasil.

ORCID: https://orcid.org/0000-0001-9881-5483.

\section{Sobre 0 artigo}

Recebido em 23 de janeiro de 2018. Aprovado em 18 de dezembro de 2018. 